\title{
New DKA in a geriatric patient on immune checkpoint inhibitor therapy: a case report
}

\author{
Anton Nikouline ${ }^{1}\left[\right.$ (]) Mike Brzozowski $^{2}$
}

Received: 21 February 2021 / Accepted: 5 May 2021 / Published online: 16 May 2021

(c) The Author(s), under exclusive licence to Canadian Association of Emergency Physicians (CAEP)/ Association Canadienne de Médecine d'Urgence (ACMU) 2021

Keywords Immune checkpoint inhibitors · Diabetic ketoacidosis · Immunotherapy $\cdot$ Critical illness $\cdot$ Emergency medicine

\section{Introduction}

Diabetic ketoacidosis is a critical illness requiring early identification and treatment. Diabetic ketoacidosis has no definitive diagnostic criteria but is hallmarked by the presence of hyperglycemia, acidosis and ketones [1]. Diabetic ketoacidosis remains primarily a disease of the young with mortality ranging from 0.65 to $3.3 \%$ [1]. Recently, there has been more published concerning atypical diabetic ketoacidosis presentations with normal glucose levels secondary to sodium-glucose cotransporter-2 (SGLT2) inhibitors [1]. Along with hyperosmolar hyperglycemic states, these create diagnostic uncertainty when evaluating older and often more comorbid patients. Here, we present a case of a previously non-diabetic patient presenting to a Canadian tertiary cancer center in diabetic ketoacidosis.

\section{Case}

An 87-year-old woman presented to the emergency department (ED) with a multiple day history of nausea and lethargy. Her past medical history included metastatic melanoma and a previous lobectomy for adenocarcinoma. Her only

Anton Nikouline

anton.nikouline@mail.utoronto.ca

Mike Brzozowski

Mike.Brzozowski@sunnybrook.ca

1 Division of Emergency Medicine, Department of Medicine, University of Toronto, C. David Naylor Building, 6 Queen's Park Crescent West, Third Floor, Room 304, Toronto, ON M5S 3H2, Canada

2 Department of Emergency Medicine, Sunnybrook Health Sciences Center, Toronto, ON, Canada medication was nivolumab and had completed three cycles in the previous month. She did not have a known history of diabetes or metabolic syndrome. She had no history of previous venous thromboembolism. She denied any vomiting, abdominal pain, dysuria, fever, cough, shortness of breath, or chest pain.

Upon presentation to the ED, her vital signs were heart rate 109 , blood pressure $142 / 53$, temperature $35.2^{\circ} \mathrm{C}$, and oxygen saturation of $95 \%$ on $3 \mathrm{~L}$ by nasal prongs. On physical examination, the patient was tachypneic. She was alert and oriented with Glasgow Coma Scale 15. She did not have any wheeze or crackles on auscultation and no murmurs were identified. She had no peripheral edema or calf tenderness. Her abdomen was soft and non-tender. Her pointof-care glucose was $33 \mathrm{mmol} / \mathrm{L}$.

Rapid venous blood gas testing showed metabolic acidosis and inadequate respiratory compensation with a $\mathrm{pH}$ of $6.95, \mathrm{pCO}_{2}$ of $25 \mathrm{mmHg}$ and $\mathrm{HCO}_{3}$ of $5 \mathrm{mmol} / \mathrm{L}$; this prompted the addition of serum ketones. Urea, aspirin, acetaminophen and toxic alcohol levels were not ordered as it was felt to not be in keeping with the patient's presentation. The patient was initially treated with $2 \mathrm{~L}$ boluses of ringer's lactate. As laboratory results were pending, the patient was started on a bicarbonate infusion to treat her severe acidemia in the interim. The patient subsequently was found to have an anion gap of $35 \mathrm{mmol} / \mathrm{L}$, glucose of 42.7 $\mathrm{mmol} / \mathrm{L}$ and positive ketones (Table 1 ). She was, therefore, diagnosed with diabetic ketoacidosis, given 10 units of insulin glargine subcutaneously and started on an insulin infusion of $0.1 \mathrm{units} / \mathrm{kg} / \mathrm{h}$. She was admitted to the intensive care unit and treated with the institutional standardized diabetic ketoacidosis protocol. She was transitioned to subcutaneous insulin the following day and transferred to the ward. She was discharged on post-admission day 5 after diabetes education and home supports were in place. The patient remains 
Table 1 The patient's laboratory values

\begin{tabular}{|c|c|c|}
\hline Laboratory test & Value & Normal Range \\
\hline Hemoglobin & $155 \mathrm{~g} / \mathrm{L}$ & $115-155 \mathrm{~g} / \mathrm{L}$ \\
\hline White blood cell count & $20.4 \times 10^{9} / \mathrm{L}$ & $3.5-10.5 \times 10^{9} / \mathrm{L}$ \\
\hline Platelets & $370 \times 10^{9} / \mathrm{L}$ & $130-380 \times 10^{9} / \mathrm{L}$ \\
\hline Sodium & $138 \mathrm{mmol} / \mathrm{L}$ & $135-145 \mathrm{mmol} / \mathrm{L}$ \\
\hline Potassium & $5.3 \mathrm{mmol} / \mathrm{L}$ & $3.5-5 \mathrm{mmol} / \mathrm{L}$ \\
\hline Chloride & $100 \mathrm{mmol} / \mathrm{L}$ & $98-107 \mathrm{mmol} / \mathrm{L}$ \\
\hline Bicarbonate & $3 \mathrm{mmol} / \mathrm{L}$ & $21-32 \mathrm{mmol} / \mathrm{L}$ \\
\hline Anion gap & $35 \mathrm{mmol} / \mathrm{L}$ & $5-12 \mathrm{mmol} / \mathrm{L}$ \\
\hline Creatinine & $139 \mu \mathrm{mol} / \mathrm{L}$ & $22-75 \mu \mathrm{mol} / \mathrm{L}$ \\
\hline Glucose & $42.7 \mathrm{mmol} / \mathrm{L}$ & $4-11 \mathrm{mmol} / \mathrm{L}$ \\
\hline ALT & $21 \mathrm{IU} / \mathrm{L}$ & 17-63 IU/L \\
\hline ALP & $148 \mathrm{IU} / \mathrm{L}$ & 50-136 IU/L \\
\hline Bili & $<3 \mu \mathrm{mol} / \mathrm{L}$ & 3-17 $\mu \mathrm{mol} / \mathrm{L}$ \\
\hline Lipase & $93 \mathrm{IU} / \mathrm{L}$ & 73-393 IU/L \\
\hline $\mathrm{Ca}$ & $2.5 \mathrm{mmol} / \mathrm{L}$ & $2.12-2.2 \mathrm{mmol} / \mathrm{L}$ \\
\hline Alb & $46 \mathrm{~g} / \mathrm{L}$ & $34-50 \mathrm{~g} / \mathrm{L}$ \\
\hline $\mathrm{PO} 4$ & $1.94 \mathrm{mmol} / \mathrm{L}$ & $0.81-1.58 \mathrm{mmol} / \mathrm{L}$ \\
\hline $\mathrm{Mg}$ & $0.95 \mathrm{mmol} / \mathrm{L}$ & $0.74-1.03 \mathrm{mmol} / \mathrm{L}$ \\
\hline $\mathrm{pH}(\mathrm{VBG})$ & 6.95 & $7.35-7.45$ \\
\hline $\mathrm{pCO}_{2}(\mathrm{VBG})$ & $25 \mathrm{mmHg}$ & $35-45 \mathrm{mmHg}$ \\
\hline $\mathrm{HCO}_{3}(\mathrm{VBG})$ & $5 \mathrm{mmol} / \mathrm{L}$ & $21-32 \mathrm{mmol} / \mathrm{L}$ \\
\hline Lactate & $4.6 \mathrm{mmol} / \mathrm{L}$ & $0.5-2.5 \mathrm{mmol} / \mathrm{L}$ \\
\hline Base deficit & $28 \mathrm{mmol} / \mathrm{L}$ & $-2-3 \mathrm{mmol} / \mathrm{L}$ \\
\hline Serum ketones & Positive & Negative \\
\hline Troponin & $30 \mathrm{ng} / \mathrm{L}$ & $<15 \mathrm{ng} / \mathrm{L}$ \\
\hline Urine leukocytes & Negative & Negative \\
\hline Urine nitrites & Negative & Negative \\
\hline Urine ketones & Positive & Negative \\
\hline TSH & $2.4 \mathrm{mIU} / \mathrm{L}$ & $0.34-5.60$ \\
\hline Hgb alc & $8.5 \%$ & $4.8-6 \%$ \\
\hline Cortisol (A.M.) & $570 \mathrm{nmol} / \mathrm{L}$ & $185-624$ \\
\hline C-Peptide & $40 \mathrm{pmol} / \mathrm{L}$ & 500-2700 pmol/L \\
\hline
\end{tabular}

Values outside of normal range were bolded

$A L T$ alanine aminotransferase, $A L P$ alkaline phosphatase, $V B G$ venous blood gas, $\mathrm{pCO}_{2}$ partial pressure of carbon dioxide, $\mathrm{HCO}_{3}$ bicarbonate

insulin-dependent 9 months after her initial presentation with a new diagnosis of type 1 diabetes secondary to her cancer immunotherapy. The patient decided to discontinue immunotherapy due to concern for further complications.

\section{Discussion}

Our case demonstrates a new cancer treatment induced diabetes presenting as diabetic ketoacidosis in an elderly patient with no previous history of diabetes.
Immune checkpoint inhibitors are a group of cancer immunotherapies that target cytotoxic $\mathrm{T}$ lymphocyteassociated protein-4 (CTLA-4), programmed cell death-1 (PD-1) and PD-ligand 1 (PD-L1) [2]. They have shown great benefit in treating advanced cancers and are fast becoming a more prevalent therapy [3]. The first immune checkpoint inhibitor, ipilimumab, was approved by the FDA in 2011 for melanoma treatment [4]. There are now 7 immune checkpoint inhibitors approved for a multitude of cancers and at different stages of disease [4]. Recent studies have shown a unique risk for immune-related endocrine organ complications in approximately $4-30 \%$ of patients with hypophysitis and thyroiditis being most common. A recent systematic review demonstrated diabetes is a lifethreatening complication in $1 \%$ of patients on immune checkpoint inhibitor therapy [2]. Approximately 50-75\% of these patients will first present with diabetic ketoacidosis, and therefore, early recognition and management by emergency physicians is vital [2]. Developing immune checkpoint inhibitor diabetes (ICI-DM) is currently thought to be secondary to pancreas/ $\beta$ cell inflammation, with $50 \%$ of cases developing asymptomatic lipase elevation [2]. The average age of these patients is approximately 65 years old; much older and with more comorbidities than typical diabetic ketoacidosis patients [2,3]. Currently there are very little data but current estimates are $5.58 \%$ of ICI-DM cases result in death, possibly due to the patient population's baseline health [3]. While further research is required to confirm, risk factors for developing ICI-DM seem to be combination therapy, PD-1 or PD-L1 agents and previous autoimmune diseases [2]. Onset of symptoms can range from a few weeks after the first cycle to 1 year, but patients typically present in short time courses with fulminant diabetic ketoacidosis [2]. There also seems to be an increase in prevalence since these medications were introduced from $0.67 \%$ in 2015 to $1.83 \%$ in 2019 [3]. Furthermore, the incidence of developing ICI-DM is greater than euglycemic diabetic ketoacidosis from SGLT2 inhibitors $(<0.1 \%)$ [1].

Management of these patients is typically centered around early diagnosis and treatment with intravenous (IV) insulin [2,3]. Steroids do not seem to have any added benefit despite the cause being autoimmune-related [2]. Interestingly, the clinician in this case treated the patient with an initial dose of insulin glargine prior to initiating IV insulin therapy. Although there is some evidence for decreased lengths of stay and incidence of rebound hyperglycemia, this has not been tested in immune checkpoint inhibitor diabetic ketoacidosis patients and is not in diabetic ketoacidosis management guidelines [5].

ICI-DM presents a new diagnostic entity that every emergency clinician should be made aware of due its atypical patient population, increasing prevalence and 
increased mortality. Due to availability bias, older cancer patients are typically evaluated for infectious, metastatic or prothrombotic etiologies that may delay recognition of diabetic ketoacidosis. Clinicians may attribute the hyperglycemia present to other disease entities, such as sepsis, especially in patients with no prior history of diabetes. Due to its increasing prevalence, unique patient population and increased mortality, awareness of these new immunotherapies is imperative. It is vital for emergency physicians to be aware of this disease entity to allow for early and prompt management.

Author contributions Dr. AN prepared the manuscript and Dr. MB was the supervising physician.

Funding No funding was received for this project.

\section{Declarations}

Conflict of interest No conflict of interest to disclose.

\section{References}

1. Goguen J. Diabetes Canada I clinical practice guidelines-chapter 15: hyperglycemic emergencies in adults [Internet]. 2018. https://guidelines.diabetes.ca/cpg/chapter15\#f0010. 18 Feb 2021

2. De Filette JMK, Pen JJ, Decoster L, Vissers T, Bravenboer B, Van Der Auwera BJ, et al. Immune checkpoint inhibitors and type 1 diabetes mellitus: a case report and systematic review [Internet]. Eur J Endocrinol. 2019;181:363-74.

3. Liu J, Zhou H, Zhang Y, Fang W, Yang Y, Huang Y, et al. 2020 Reporting of immune checkpoint inhibitor therapy-associated diabetes, 2015-2019. Diabetes Care. 2020;43:E79-80.

4. Vaddepally RK, Kharel P, Pandey R, Garje R, Chandra AB. Review of indications of FDA-approved immune checkpoint inhibitors per NCCN guidelines with the level of evidence [Internet]. Cancers. 2020;12:738.

5. Barski L, Brandstaetter E, Sagy I, Jotkowitz A. Basal insulin for the management of diabetic ketoacidosis. Eur J Internal Med. 2018;47:14-6. 